\section{The use of resilience-based group intervention program for victims of bullying}

Tolentino, Marvin $\$

Central Luzon State University, Philippines (tolentinomarvin@gmail.com)

Suba, Elizabeth

Central Luzon State University, Philippines (bssuba@yahoo.com)

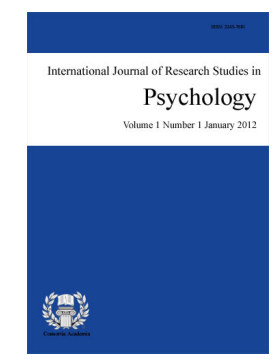

ISSN: 2243-7681 Online ISSN: 2243-769X

OPEN ACCESS

\title{
Abstract
}

This paper investigated the level of resilience of seventy-two (72) public Grade-7 and Grade-8 students in Sto. Domingo, Nueva Ecija who were victimized by bullying and tested the usefulness of the Resilience-based Group Intervention (RBGI) for fifteen (15) purposively selected participants. The study also looked on the bullying victimization experiences of the respondents using multiple checklist survey forms. It also documented the result of focused group discussions and activities during the 8-session intervention which centered on enhancing the participants' capacity to sustain supportive parent-child relationship, developing adaptive thoughts and providing positive peer activities. Finally, the differences on the level of resilience before and after the conduct of RBGI were measured using the 10-item Connor-Davidson Resilience Scale (CD-RISC 10). The results of the study showed that the most common bullying victimization experience of the participants was in the form of verbal bullying. The RBGI, which used millennial techniques during reflective exercises and creative narratives activities, was able to build proper rapport among the group, captured their own concept of resilience, process their past experiences on bullying victimization, stirred discussions about parent-child relationship, and enhanced their adaptive thinking skills. The participants were also able to develop simple behavioral plan in case of future adversity. The paper concluded that group approach in building resilience among youth victimized by bullying was a doable and viable school intervention. Therefore, the researcher encouraged guidance professionals to employ and integrate the RBGI program to homeroom guidance, values education classes, as well as in community and youth activities.

Keywords: resilience; group intervention; bullying; Filipino; youth 


\section{The use of resilience-based group intervention program for victims of bullying}

\section{Introduction}

The impact of any mental health intervention is gauged by how effective it capacitates individuals to thrive despite different life adversities. Today, guidance and counseling programs are considered as key service for youth who face different personal, academic and relational challenges; wherein some seem too tough to handle by one's family and concerned academic personnel. By offering such service, school administrators are assured that they attend well to both general and special concerns of students through the delivery of therapeutic and capacity-building intervention.

For the past decades, students are confronted not only by academic challenges but more so by problems which involve social violence and aggression in form of bullying. Bullying takes many forms which include physical, verbal or psychological abuse (Council for the Welfare of Children and UNICEF Philippines, 2016; Cardona, Reyes, \& Tangalin, 2015; William \& Guerra, 2007). It is generally executed either through actual or virtual means, especially now that social media is readily available and can be used immensely as tool for 'bashing' someone with an offender not easily getting identified. Also, bullying is evident not only in schools from developing countries but also from the developed ones. Lastly, bullying might not only occur within the student population but might be a covert practice by some adult authorities. This indicates that any student from any origin can be subjected to any form of cruelty by anyone when he or she is targeted as victim. Bullying therefore is a kind of social problem that is becoming prevalent among youth.

Mental health professionals including school counselors and educators are continuously devising different intervention that could provide help and assistance to students who are victimized by bullying. Some are in forms of individual counseling, school campaigns, parent consultation and disciplinary measures among the abusers or the 'bullies'. While such measures are recognized as helpful to decrease the incidence, this study explored alternative intervention that centers on enhancing the strength of victims of bullying; hence, a resilience-based group intervention. Resilience has been generally defined as the capacity of an individual to 'bounce back' to normal and effective functioning following a debilitating experience (National Scientific Council on the Developing Child, 2015; VicHealth, 2015; Luthar \& Cicchetti, 2000). In the context of school bullying, a seemingly weak individual must still be able to develop his personal and academic potentials even when he was mistreated or underestimated.

During the previous years, resilience has become a primary research interest for academicians, policymakers and mental health practitioners due to its potential implications on understanding and improving one's health, well-being and quality of life (VicHealth, 2015). The growing concerns related to bullying among youth not to mention the emergent need to combat teenage depression stirred the researcher's interest to come up with the study that aims to build resilience among youth, specifically the victims of bullying.

The study investigated the level of resilience among victims of bullying. Specifically, it determined the respondents' socio-demographic characteristics (SDCs) in terms of age, sex, grade level and parental presence at home, described the respondents' experiences as victims in terms of physical, verbal and social bullying, and determined the level of resilience of the respondents before the conduct of the resilience-based group intervention (RBGI). The study also described the resilience level of the respondents according to age groupings, sex and parental presence and determined the difference of the participants' level of resilience before and after the conduct of the RBGI. 


\section{Review of related literature}

\subsection{Definition of Bullying and Its Forms}

Filipino researchers, Cardona, Reyes, and Tangalin (2015) defined bullying as a repeated verbal, physical, social or psychological aggressive behavior by a person or group directed towards a less powerful person or group that is intended to cause harm, distress or fear. Also called peer violence by the Council for the Welfare of Children and UNICEF Philippines (2016), bullying is unwanted, aggressive behavior among school-aged children that involves a real or perceived power imbalance which makes use of force, threats, or coercion to abuse, intimidate, or aggressively dominate others. The behavior is often repeated and habitual. Bullying is therefore a kind of social aggression that is most observable in schools, than in other social avenues. However, what sets bullying apart from other aggressive attacks is its 'repeated' nature, which is reinforced by the silence and powerlessness of the victim (Bibou-Nakou, Tsiantis, Assimopoulos, Chatzilambou, \& Giannakopoulou, 2012).

With today's technological advances and the youth's increasing social media exposure, bullying has been also elevated into such form. According to Ancho (2014), cyber-bullying has been included as an aggressive behavior with the use of electronic materials that inflict harm, intimidation, or humiliation. A related term of "child cyber-violence" was also coined by the Center for the Welfare of Children and UNICEF Philippines (2016) that pertains to an online behavior that constitutes or leads to assault against the wellbeing (physical, psychological, emotional) of an individual or group. Such definition of bullying serves as the guide of the study on qualifying an act whether it is considered a bullying or just a playful activity among the target population.

A group of local researchers also conducted a descriptive investigation to determine the bullying experiences among Filipino students and included their teachers as respondents using interview and documentary methods. They categorized the bullying that students experience such as direct (in form of physical, verbal and psychological types) and indirect bullying. Under the direct type of bullying, students reported being pushed or shoved, beaten, kicked, as well as cases of extortion, theft, hitting, spitting, and throwing of papers. In terms of verbal bullying, they felt they were insulted, mocked, and given dirty looks. Under the psychological type of direct bullying, they reported being coerced, excluded from group and were threatened. Under the indirect type of bullying, the respondents experienced receiving insults and threats through texts and intimidating gossips through the internet. Williams and Guerra (2007) also identified four forms of aggression which were practiced in relation to school bullying: physical aggression, verbal aggression such as name calling and threats, relational aggression such as social isolation and rumor spreading. In addition, students asserted cases of social bullying like spreading of hearsays and vandalism (Cardona, Reyes, \& Tangalin, 2015). In one account of Council for the Welfare of Children and UNICEF Philippines (2016), they also included the acts such as physical and verbal harm, sexual molestations, being laughed at, catcalling, avoidance of one's company, gossiping about, stalking, and taking or hiding one's personal properties- as forms of bullying among youth and children.

Such accounts provided recent and local references on the current forms and practice of bullying among youth, especially Filipinos. The study also ventured to know the bullying experiences of targeted high school student population and was also limited to describing the experience with focus on creating intervention.

\subsection{Recent Bullying Studies in the Philippines}

The Department of Education (DepEd) documented more than 1,700 cases of bullying during the school year 2013-2014 and $60 \%$ were only resolved according to Flores (2014). On a national account performed by the Center for the Welfare of Children and UNICEF Philippines (2016), they included 3, 866 young respondents aged 13-24 to profile the violence done against Filipino children. Out of the different strands of child violence, peer violence or bullying had accounted for the $65 \%$ among the respondents who had experienced such act. Females reported higher lifetime prevalence during childhood (70\%) than their male counterparts $(59.8 \%)$ on the 
experience of bullying. However, when the researchers inquired on how aware were the respondents on the services they could utilize for such need, only 1 in 10 respondents reported having consulted their guidance counselors.

Another local study on bullying was that of Gerardo (2016) which focused on determining the types and extent of bullying among the high school students in Cagayan. The paper found out that almost all respondents had experienced the three types of bullying (physical, social and verbal) which lasted for an average of less than a week. It also concluded that such forms of bullying were able to negatively affect the respondents' well-being: physical, emotional, intellectual, social, behavioral and creative.

Age and grade level - Another interesting finding on the study of Cook, Williams, Guerra, Kim, and Sadek (2010) also showed that age significantly moderated the effect of internalizing behavior (e.g., being withdrawn, depressive, anxious, and avoidant responses) for bullying victims, with victims exhibiting more internalizing behaviors as they transitioned into adolescence.

In terms of bullying victimization, it was found out that older students (such as those who are in the third year of high school) were more assertive and sought more autonomy than primary school students (Bibou-Nakou, Tsiantis, Assimopoulos, Chatzilambou, \& Giannakopoulou, 2012). According to Fonzi and colleagues (2002), the number of victims is at its highest at the elementary level until the beginning of secondary level when the level of victimization tends to decrease. Similar finding on the local study of Reyes (2012) had been found that the lower the grade level students are in, the higher is the involvement in bullying. In another study conducted by the Cyberbullying Research Center, the emotional repercussions of bullying across age groups were observed. They discovered that senior and junior high students mainly responded to bullying through anger and frustration, as compared to elementary students who were more likely to feel sad as a result of being bullied (Hinduja \& Patchin, 2009).

Sex - The prevalence of peer violence or bullying among Filipino children was higher among females (70.5\%) than males (59.8\%). About 35.4 percent experienced bullying in the past 12 months (UNICEF Philippines, 2016). The study of Cook, Williams, Guerra, Kim, and Sadek (2010) presented a comprehensive effort to synthesize systematically predictors of bullying and victimization based on research conducted over the past 3 decades of literature. They found out that boys appeared more involved in bullying than girls across all bully status groups (bully, victim, bully victim). This means that more boys tend to be a bully, victim and/or bully victim than girls for the past 30 years.

Based on a 2010 study involving a random sample of 2,212 teen males and 2,162 teen females, the male to female ratio varied the most in the following areas: victimization within a person's lifetime (16.6\% for males vs. $25.1 \%$ for females) and had a hurtful comment posted about oneself online (10.5\% for males vs. $18.2 \%$ for females). It is interesting that females reported a higher percentage in both categories (Hinduja \& Patchin, 2010). While, the study conducted by the Cyberbullying Research Center on 468 students revealed that females were typically more emotionally affected (such as being frustrated, angry and sad) because of bullying than males (Hinduja and Patchin, 2009). The study of Underwood and Rosen (2011) revealed that girls more often identified themselves as victims of social bullying such as gossip in cyberspace. While observations from the study of Rodkin and Berger (2008) suggested that girls were more likely to be involved as victims while boys were more likely to participate as bullies or bully-victims. Atlas and Pepler (2001) also investigated gender differences in frequency of bullying and victimization. Using naturalistic observation in the classroom setting, the researchers observed that boys and girls were equally likely to bully at rate of approximately two (2) episodes per hour.

Home environment - Swearer and Doll (2001) found out that children's number of siblings is positively correlated to higher tendencies that younger siblings get bullied by older siblings. Kumpulainen and colleagues (1999) explained that high number of siblings is a factor of sibling abuse and the need to engage in more competitive behavior as strategy to gain status and leadership exists within siblings. The study of Reyes (2012) also revealed that bullying victims and perpetrators both have number of siblings that ranged from 1 to 3 . 
Insecure parental attachments during infancy as well as intrusive and overprotective parenting are seen to be linked with children being chronically victimized by bullying according to the study of Perry, Hudges, and Edgar (2001). However, Orpinas and Home (2005) identified parental behaviors that were seen to be protective factors against involvement of children in bullying problems. This included communicating love and warmth, monitoring their children, setting age-appropriate limits and using non-physical punishments. Cook, Williams, Guerra, Kim, and Sadek (2010) also concluded that home environment significantly predicted involvement for both bullies and victims which indicated the important role social context plays in the development and maintenance of bullying. A pupil who has a complete family is more likely to show favorable behavior compared to those who have a single parent and are abandoned (Tiongco, 2010). Such cited studies indicated the significance and extent of bullying incidences in the recent years both in international and local investigations.

\subsection{Psychological Profile of the Bully and the Victim}

The following sections present important and relative details which would allow the readers make a grasp about the psychological profiles of both the bully and the victim.

Ross (2002) found that those children who witnessed aggressive behaviors at home and experienced inconsistent feelings of safety and love had a likely chance of becoming bullies when they enter school. Another noteworthy research about bullying was that meta-analysis study of Cook, Williams, Guerra, Kim, and Sadek (2010). They aimed to examine factors that predicted bullying and victimization in childhood and adolescence across multiple investigations (electronic, published and non-peer-reviewed materials) by reviewing articles from 1970s to mid-2006. Based on their findings, the typical bully is one who has both social competence and academic challenges, possesses negative attitudes and beliefs about others, has negative self-related cognitions, has trouble resolving problems with others, comes from a family environment characterized by conflict and poor parental monitoring, is more likely to perceive his or her school as having a negative atmosphere, is influenced by negative community factors, and tends to be negatively influenced by his or her peers, among others. Meanwhile, The Center for the Welfare of Children and UNICEF Philippines (2016) discovered that almost half of the bullying was perpetrated by schoolmates and close friends, during their investigation from 3,866 young respondents all over the Philippines.

The national baseline account of violence against children by The Center for the Welfare of Children and UNICEF Philippines (2016) found out that the common triggers for bullying were physical appearance, status in life and skin color. Other researchers have found out personality characteristics and profile linked to students who tend to be victims of bullying. According to Cook, Williams, Guerra, Kim, and Sadek (2010), the typical victim is one who is likely to lack adequate social skills, possess negative self-related cognitions, experience difficulties in solving social problems, comes from negative community, family, and school environments, and be noticeably rejected and isolated by peers. Ross (2002) also categorized bully victims into two: passive and provocative victims. Passive victims tend to have characteristics such as low self-concept and self-confidence. They are emotionally sensitive and have fears of inadequacy. This type of victims also tends to be physically smaller and weaker than other children their age and have ineffective social skills or poor interpersonal skills. They often internalize and blame themselves for any issues that arise. On the other hand, provocative victims are "far more assertive, confident, and active than other victims and are noted for prolonging a fight even when they are losing" (Ross, 2002, p. 118). They are usually volatile, aggressive, and create management problems at school. Provocative types have very few friends because they lack social skills.

\subsection{On Addressing School Bullying}

The following cited accounts provide pointers on how to effectively address the problems on bullying through the conduct of different programs.

The study of Cook, Williams, Guerra, Kim, and Sadek (2010) argued that there is more to evaluating the 
predictors of bullying than conducting individual-level analysis. That is to include home environment, school climate, peer influences and community factors in viewing and therefore in addressing the issue of school bullying- thus, involving one's social environment in the framework. This includes behavioral parenting training which can be combined with some form of positive peer intervention at school. Similarly according to Hepburn (1997), addressing bullying incidence must be also anchored on the deep knowledge about one's school culture and family functioning. This approach on bullying prevention is quite consistent with the interest of resilience intervention framework which is also founded on building one's resilience in the milieu of the child's social context.

After conducting semi-structured interviews among 90-students with ages ranging from 13-15 in fourteen focus groups, a group of researchers found out that the importance of building parent-child relationship among the victims of bullying was evident on the responses that home offered more room for warm and closeness which they might be deprived of at school (Bibou-Nakou, Tsiantis, Assimopoulos, Chatzilambou, and Giannakopoulou, 2012). This implies that the victims of bullying have high need to be more connected with their parents. The design of the resilience-based group intervention in this present study was also directed toward the establishment of supportive parent-child relationship. Warm and supportive parenting seems to moderate the adverse effects of bullying to its victims. Still in the context of school aggression, Barbero, Hernandez, Esteban, and Garcia (2012) posited that the most effective interventions appeared to be those aimed at improving social and interpersonal skills and modifying attitudes and beliefs. Building resilience among the victims of bullying in this present study was also aimed at developing the adaptive ability of the respondents by teaching them healthy and empowering thoughts and cognitions related to self and dealing with failures.

Bickmore (2011) also noted that schools that enjoyed non-violence observed a variety of activities participated in by students, as opposed to those institutions that stressed control and punishment. This could imply that school must also create an environment that encourage students cultivate positive experience and harness their abilities as a way to divert students' attention from violence to camaraderie. One of the aims of intervention used in the present study was to assist participants to cultivate positive experiences that would build a sense of self-worth among them. The foregoing sets of empirical reviews provided the nature and dynamics that happened between the actor and target of bullying as well as possible approach on combatting such form of peer violence. To help reduce such power imbalance among youth, the present study became interested to build upon the strength of the victims of bullying by enhancing and building their resilience.

Reyes (2012) devised a school intervention program specifically designed to address bullying problems among school-aged youth. The program was created based on the study which investigated factors of bullying among public elementary school pupils at a city in Nueva Ecija, Philippines. The program aimed to provide self-awareness activities for students for both bullying perpetrators and victims. Specific activity was designed for students who were victimized by bullying using the interactive story telling wherein the group had to gather information about other children's experiences and acted as peer advisors while under the guidance of teacher or school counselor. The activity aimed to help the group build self-image and positive peer relationship, as well as manage anxiety. Film showing, guided story-telling, assigned role-playing and drawing were among the activities of the said program.

The group intervention used in this study also provided activities that teach the group to tell and retell their stories, express their thoughts through drawing and establish better peer relationships.

\subsection{What is Resilience?}

Resilience is defined as the capacity of an individual to adapt well on adversity and life stresses (National Scientific Council on the Developing Child, 2015; VicHealth, 2015). The National Scientific Council on the Developing Child (2015) identified the set of common and defining features of resilience which included the individual's adaptive ability and the process of harnessing personal and collective resources to 'bounce back' on 
effective functioning following adverse situations which threatened well-being such as stress, trauma or poverty. To Greenberg (2006), resilience is generally the protective processes that reduce maladaptive outcomes under conditions of risk. Such protective factors that are especially essential under conditions of risk are categorized into three broad types: characteristics of the individual (temperamental qualities, cognitive ability), the quality of the child's relationships, and broad ecological factors such as quality schools, safe neighborhoods and regular activities.

Given the previous definitions, resilience can be viewed as both referring to individual's capability and the helpful dynamics in the environment as one experiences difficult life circumstance. This is consistent with Masten, Best, \& Garmezy's definition of resilience as “the process of, capacity for, or outcome of successful adaptation despite challenging or threatening circumstances" (as cited in Alvord \& Grados, 2005). Luthar (as cited in Luthar \& Cicchetti, 2000) also emphasized that resilience is a process or phenomenon (of positive adaptation despite adversity), and explicitly clarified that it is not a single personal characteristics of the individual. Therefore resilience, as a dynamic process wherein individuals display positive adaptation despite experiences of significant adversity or trauma, characterizes the two-dimensionality of the construct. Adversity, also referred to as risk, typically encompasses negative life circumstances while positive adaptation represents the behavioral manifestation of social competence and successful accomplishments of various developmental tasks (Luthar \& Cicchetti, 2000).

Given this widely accepted concept, the present study viewed resilience as the person's perceived capability to adapt well in the presence of an adversity.

\subsection{Factors of Resilience}

A research has identified a set of factors that help children achieve positive outcomes in the face of significant adversity (Center on the Developing Child, 2015). Factors that optimize resilience across multiple contexts include: reassuring adult-child relationships, support on developing child's sense of self-efficacy and control, strengthened adaptive skills and self-regulatory capacities and the use of faith and cultural traditions as a foundation for hope and stability. Aside from having caring and supportive relationships within and outside the families as primary factor in resilience, there are also additional factors associated with resilience. These include the capacity to make realistic plans and take steps to carry them out, a positive view of oneself and confidence in one's strengths and abilities, skills in communication and problem solving and the capacity to manage strong feelings and impulses.

The study is particularly interested on providing intervention to students who were victimized by bullying in the area of parent-child relationship enhancement and adaptive skills development. It is with the hope that this would facilitate an improved level of resilience among the participants.

Based on a broad consensus of different sources in the past decades, Newman (2002) similarly categorized the factors which can promote childhood resilience located in three domains: the physical and emotional attributes of the child, the child's family, and the immediate environment where the child lives. The child's easy temperament, being active and good-natured, high IQ, good social skills with peers and adults, personal awareness of strength and limitations, feelings of empathy for others, internal locus of control, sense of humor and attractiveness to others help build resilience. On family aspect, warm and supportive parents, parental harmony, good parent-child relationships (especially when parental disharmony is present) and a valued social role in household facilitate resilience among children. Lastly, environmental factors that promote resilience among children include supportive extended family, successful school experiences, valued social role such as job, volunteering or helping neighbors, a close relationship with unrelated mentor, membership of religious faith community and extra-curricular activities.

In effect, resilience among individuals operates when they are provided with supportive relationships, adaptive skill-building and positive experiences. For youth to determine his resilience, he must therefore look on 
his individual and family assets as well as social support. Supportive relationship with pro-social adult caregiver provides them personalized responsiveness and protection from developmental disruption. Adaptive skill-building shapes their capacities to plan, monitor and regulate behavior during adversity, and thrive. Positive experiences on their respective community preserve their own social worth as a person. Being cognizant on this wide consensus about the factors of resilience, the study used these three factors (supportive parent-child relationship, adaptive skill-building and the cultivation of positive experiences in school) as baseline strategies for enhancing the resilience among the students who were victimized by bullying.

\subsection{Resilience among Children}

Resilience among children and youth had been explored in different contexts such as poverty, natural disasters, physical ailments, and violence. While resilience studies adapted a variety of framework, what was similarly being found across such studies was the important role of supportive relationships that children have on their family and/or community (Engle, Castle, \& Menon, 1996; Gebru, 2009). In the context of community violence, factors on children's resilience included the existence of at least one stable and supportive relationship, along with the understanding of the reasons for the violence and a belief in a higher purpose, among others (Engle, Castle, \& Menon, 1996).

On a different study that aimed to determine the processes that contributed to resilience among youth in foster care, researchers Drapeau and colleagues (2007) identified a group of twelve (12) resilient boys and girls being placed in the foster care on the average of more than seven (7) years. Findings from the study suggested that among the processes linked to youth resilience included increase in perceived self-efficacy and new opportunities, among others. Reviewing from different studies conducted in the past, Gebru (2009) found out that poor children actively implemented ways to cope with poverty and the protective factors that helped reduce the negative impacts of poverty on their well-being included supportive relationships with family members, friends and the neighborhood. This also led to the conclusion that the types of family the children had influences on how they perceived the risks which threatened their well-being.

To be more specific, researchers Sapouna and Wolke (2013) inquired about the individual, family and peer predictors of students who manifested resiliency despite being bullied using longitudinal study. Self-report data were included from 3,136 sampled adolescents to measure bullying victimization at ages 13 and 14 . Using regression analysis, it was found out that the adolescents who reported low depression despite frequently experiencing bullying tended to be male, had higher self-esteem, were feeling less socially alienated, were experiencing low levels of conflict with parents and were not victimized by siblings. The study concluded that relationships with parents and siblings continued to play some role in promoting emotional and behavioral adjustment among victims of bullying and, therefore, interventions were more likely to be successful if they targeted both the psychosocial skills of adolescents and their relationships with their family.

A dissertation conducted by Wade (2007) offered explanation on the difference between those victims who showed the typical negative effects of bullying, and those who demonstrated resilience. According to the findings, the difference was related to a set of skills and attitudes that provided victims with a buffer against the negative consequences associated with being a victim. These skills and attitude include: being optimistic, using productive coping strategies, having a healthy self-esteem and self-concept, possessing social skills, and perceiving a high level of social support in one's life. These skills and attitudes also appeared to be amenable to change through participation in a cognitive-behavioral group-based intervention program.

Again, in this present study, the researcher aimed to include the aspect of enhancing adaptive psychosocial skills as well as building and maintaining supportive parent-child and peer relationship on the proposed group intervention for students who were victimized by bullying. 


\subsection{Resilience-based Interventions}

Different studies in the past had focused on reviewing the effectiveness of resilience-based interventions specifically offered on individual, family and community levels (Rutter, 1997; Luthar \& Cicchetti, 2000; Alvord \& Grados 2005; LeMoine \& Labelle, 2014; Ungari, Russell, \& Connelly 2014; VicHealth, 2015; Dray, Bownan, Wolfenden, Campbell, Freund, Hodder, \& Wiggers, 2015), and Hechanova and colleagues (2015).

To Rutter (1997), resilience-promoting interventions tend to be more beneficial when children are exposed to manageable demands and opportunities to succeed in valued tasks wherein they will develop more competencies and grow in self-esteem. Also, those children that are taught coping strategies and skills, and being helped to view negative experiences positively capacitates them to re-frame experiences thereby increasing their chance to be more resilient in the future. The goal of this study was to develop a group intervention for victims of bullying that focused on enhancing the students' healthy thinking about themselves and their situation.

The resilience framework of Luthar and Cicchetti (2000) provided evidence-based knowledge on vulnerability and protective processes that can help individuals within the context of a specific adversity. Based on such knowledge, they provided guiding principles that can be helpful in designing resilience-based intervention programs for youth. To them, interventions must be theoretically grounded and must have strong basis in research on the particular group being targeted. Efforts must not only focus on the reduction of negative outcomes but also toward the promotion of positive adaptation and to capitalize on specific resources on different levels (community, family, individual) of the targeted groups. That is building upon the strength of people in the community. Contextual relevance of the intervention aims and strategies must be ensured through collaborative participation among its stakeholders. Intervention efforts should aim at fostering services that eventually can become self-sustaining. The intervention must be carefully documented and evaluated as its essential components. As implications for future interventions, resilience-based intervention must be a comprehensive program that is integrated into the child's educational program, cultural context and personal behavioral repertoire rather than fragmented efforts (Luthar \& Cicchetti, 2000). Such framework is beneficial to the present study since the author targets students and aims for the educational sector to collaborate in the planning, adopt the program and possibly integrate it to the school curriculum.

From the result of scoping review, Alvord and Grados (2005) identified protective factors that are related to foster resilience in children and presented a practical, proactive, resilience-based model that clinicians may use in a group intervention setting. For them, self-regulation (i.e., the ability to gain control over attention, emotions and behavior), proactive parenting (i.e., at least one warm and supportive adult caregiver), and connections and attachments (i.e., social competence and positive social relations) are some of the fundamental protective factors that build resilience among children.

This is a resilience-based curriculum that focuses on a proactive orientation and cognitive-behavioral strategies. The model entails interactive identification of protective factors with children, free play and behavioral rehearsal, training in relaxation and self-control techniques, practice in generalizing skills acquired and active parent involvement. Groups are presented to the community as 'social skills groups' to prevent any stigma related to seeking mental health services. The model is designed for 12-14 sessions per semester parallel for the academic year. Across the conduct of all components, group rules are clearly defined in the first session and reinforced with a reward system. Rules include talking one at a time, staying in one's personal space, playing cooperatively and talking nicely. A systematic behavior reward system is implemented that includes charting points for the following group rules, completing and discussing their homework, talking about their progress toward their individual goals, and the likes. Points can be traded in for a small prize every few sessions or accumulated to earn something, exposing children to the idea of delayed gratification (Alvord \& Grados, 2005).

The Alvord-Baker model implies that group intervention aiming to boost resilience among the youth must capitalize on the protective influences that may serve to buffer them from stress. The following studies show 
what can work for young individuals as recipients of resilience-based interventions.

LeMoine and Labelle (2014) assessed the relevance and quality of resilience-based interventions for youth. Having three independent reviewers and AGREE II Tool to assess identified interventions, they were able to identify the themes common to resilience-enhancing strategies at the individual, family and community levels: (a) focus on developing youth's social, emotional and personal competence skills; (b) helping them to define their own outcomes and involving them in the development of services they receive; (c) offering positive parenting programs; (d) ensuring the presence and secure relationship from a predictable and stable adult caregiver; (e) supporting youth in their ability to build social capital and connectedness with resources in the community. As implication of such findings, current theoretical views on resilience are directed towards the adaptation of the environment and systems surrounding youth, as opposed to changes at the individual level (LeMoine \& Labelle, 2014). This is consistent with the present study's baseline reference on the factors that promote resilience among youth which includes supportive parent-child relationship, adaptive skill-building activities and cultivation of positive experiences in school.

Based on the scoping study of outcomes from thirty-six (36) resilience-based interventions for middle school students, Ungari, Russell, and Connelly (2014) found that while many programs did show some positive impact on resilience-related factors for students, less successful programs tended to be those that did not consider students' cultural background or show sensitivity to environmental factors like the size of their community, access to other services and support or the economic status of the child's family. This supported the idea that resilience-based interventions could offer the most promising result when it was collaborative, multi-systemic, culturally and contextually relevant, and was responsive to what children themselves said they need. The study therefore was constructed in the light of both the children's cultural background and school values to help the conduct of the group intervention more meaningful and useful.

Aside from incorporating cultural considerations on providing such interventions, resilience-based school programs for youth must emphasize the building of children's social capital, at home with supportive adults, at school with educators, and with peers who behave in socially acceptable ways. Also, programs that both emphasize academic and non-academic goals would help youth to be more engaged at school and increase individual qualities that would predict greater success in learning. Such programs promoted cultural activities, community-based initiatives that bolstered self-esteem, connections with adults, pro-social behavior and prevention of delinquent behavior (Ungari, Russell, \& Connelly, 2014).

From these series of review, we can infer that resilience-based interventions not only prepare youth to be academically and socially successful but also empower them to achieve psychological well-being. The study of Dray, Bownan, Wolfenden, Campbell, Freund, Hodder, and Wiggers (2015) assessed the effects of universal school-based resilience-focused interventions on mental health outcomes among children and adolescents. They concluded that resilience-focused interventions strengthened protective factors that fostered the development of coping mechanisms and positive mental health. Protective factors were perceived to incorporate both internal resources (self-efficacy, coping skills and effective problem solving) and external factors (positive family and peer relationships, supportive school and community environments) to help the children thrive during challenging circumstances.

Another noteworthy resilience-building intervention was that of Hechanova and colleagues (2015) which was locally administered by group of psychologists to communities hit by recent calamities and natural disasters in the Philippines. The group named the framework Katatagan which is the closest Filipino equivalent to the word 'resilience'. The 6-week intervention program was able to rebuild resilience to trauma victims by helping them identify and cultivate their strengths (Kalakasan), identify their current concerns and seek solutions and support(Kalutasan at Kaagapay), manage their physical reactions (Katawan), manage unhelpful thoughts and emotions (Kalooban), identify positive activities (Kapaki-pakinabang na Gawain), and identify goals and develop action plans to achieve these goals (Kinabukasan). The resilience intervention was reckoned to be 
adapted and be tested its effectiveness to different population. The researcher of the present study believes that most of the Katatagan concepts can also be applied in part to the students being victimized by extreme forms of school bullying.

\subsection{Current Study}

The foregoing literature on resilience-promoting programs is often introduced within the context of substance abuse, mental health, natural disasters and domestic violence but rarely on the milieu of school bullying. Such findings and established evidences mentioned on these accounts and studies were highly observed in the planning, designing and conduct of the resilience-based intervention program for the target participants of the study.

The findings of this study would be helpful in addressing school bullying problems among victims and promoting resilience which policy-makers, school officials and its stakeholders can benefit from. The result of the study will help the students who are victimized by bullying and build their resilience for them to adapt to different difficulties that impede their personal, social and academic growth. It will also be useful in providing important insights and practicable ideas to interested guidance counselors and coordinators on how such goal of building resilience among bullying victims can be achieved using group intervention. The study can provide a ready reference for the teachers in local districts to utilize or integrate on their classroom instructions. The intervention program used in this study will have a potential usefulness and significance for addressing not only bullying-related issues but more so in other context such as substance abuse, mental health, natural disasters and domestic violence, as well as in other settings like rehabilitation, youth centers and community outreach.

This study sought to answer the following questions: a) what are the socio-demographic characteristics (SDCs) of students being victimized by bullying in terms of age, sex, grade level and parental presence at home; what are the respondents' experiences as victims in terms of physical, verbal and social bullying?; b) determine the level of resilience of the respondents before the conduct of the resilience-based group intervention (RBGI)?; c) describe the resilience level of the respondents according to age groupings, sex and parental presence?; d) determine the difference of the participants' level of resilience before and after the conduct of the RBGI?

In addressing the research questions, the study tested the following hypotheses: a) there is no difference on the respondents' initial level of resilience across age groupings, sex and parental presence at home; b) there is no significant difference on the levels of resilience among the participants prior and after the resilience-based group intervention.

\section{Method}

\subsection{Design}

The study employed a mixed method research design wherein it used both qualitative and quantitative information which were gathered through the conduct of group intervention for students who were victims of bullying. Descriptive data were gathered from the participants' socio-demographics characteristics (age, sex and parental presence), their self-report related experiences of being bullied and a resilience scale. Through the use of focused-group discussion results (narratives, essay, and drawings), the study documented the experiences and outcome of the resilience-based group intervention for students who were victims of bullying. Also, the study presented the differences on the level of resilience prior and after the conduct of the group intervention.

\subsection{Participants of the Study}

The data gathering was composed of two phases. The first phase was a bullying victimization and resilience survey which included seventy-two (72) $7^{\text {th }}$ and $8^{\text {th }}$ Grade students aged 11-14 as respondents. Meanwhile, the 
second phase was the conduct of the resilience based group intervention program which included fifteen (15) participants from the $7^{\text {th }}$ Grade. The participants were chosen based on how low the scores they obtained on the resilience scale as well as their availability to participate on the weekly sessions. The intervention participants were composed of two (2) males and thirteen (13) females whose ages ranged from 11 to 13 years old. Eleven (11) of them had their both parents living with them at home; two (2) were taken care of by other adult relatives and the other two (2) participants had their mothers who singlehandedly raise them. The respondents and the participants were purposively selected by the researcher through the help of classroom advisers. To qualify as survey respondents and intervention participants, students must have been referred to the guidance office due to bullying victimization during the previous and present academic year. Both the respondents and the participants volunteered to take part in the study with full knowledge of its purpose.

\subsection{Instrumentations}

To gather the necessary data on the participants' socio-demographic characteristics, the researcher devised a survey questionnaire that inquired about the participants' socio-demographic characteristics and a bullying victimization checklist. The questionnaire was also with an informed consent letter from the researcher.

To determine the level of resilience of the respondents, the researcher used a Filipino form of the 10-item Connor-Davidson Resilience Scale (CD-RISC 10) from the works of Connor and Davidson (2003). Signing an agreement with the test author Jonathan Davidson, MD the researcher had procured the Filipino-translated resilience scale along with the manual all the way from North Carolina, USA. The instrument was selected since it operationally defined resilience similar to the framework used in the present study. The CD-RISC form was composed of 10 items answerable by a 5-point scale. According to Hall (2010), the scale demonstrated good internal consistency and construct-validity. The test is also effectively intended to use in screening, profiling for intervention and measuring change on targeted individuals which makes it applicable for use in the present study. Based on reported test-retest reliability studies, CD RISC 10 had demonstrated a correlation coefficient of 0.90 in a Chinese Sample (Wang et al., 2010) while a Cronbach's alpha $=0.88$ was obtained from a 6-week test-retest method among Spanish patients (Notario-Pacheco et al., 2014).

The researcher also constructed a resilience-based group intervention which was derived both from actual counseling experience with students who were victimized by bullying in a private non-sectarian high school, as well as from the wide array of empirical reviews related to building youth resilience and addressing bullying. The design of the intervention aimed to strengthen the three factors of resilience: supportive adult-child relationship, adaptive skill building and cultivation of positive experience/activities. The intervention program was composed of eight (8) modules with an average running time of 90 minutes. It made use of millennial-approach focused-group activities which included self-reflection, creative narratives, written exercises and cognitive homework. Upon completing the program design, the researcher consulted three independent experts in allied fields: a registered social worker engaged in community empowerment program of the national government, a psychology professional with background in capacity-building projects and a full-time guidance counselor working in a private high school. The consultation was done to get feedback and suggestions for the improvement of the devised resilience-based group intervention program.

Along with other helpful forms and processing questions which can be used during the sessions of group intervention, the above-mentioned instruments were used accordingly to help the researcher come up with systematic data to answer the problems of the study.

\subsection{Data Gathering Procedure}

The researcher sent correspondence and scheduled an initial talk with the school principal and/or academic coordinator of JOLNHS to discuss the study. During the scheduled date of CD RISC test administration, the researcher and the year level coordinator of the school went to the selected sections to shortly discuss the test and 
its purpose with the permission of the subject teacher. Also, the consent of the respondents was obtained through a letter attached on the questionnaire. The samples were identified by discussing the selection criteria, looking for volunteers and with the help of the knowledge of their teachers. While the identified respondents were completing the test forms, the researcher transferred to other rooms until the questionnaires were completely distributed. From the respondents' list, the researcher identified intervention-groups who were willing to be included in the intervention program and those that had low levels of resilience scores. The permission of the teachers in charge to the participants was obtained.

With regard to the resilience-based group intervention, the program was composed of eight (8) structured learning activities with an estimated time of 90 minutes per session that was administered weekly. The modules were conducted at the school setting and the schedules were closely coordinated to the academic coordinator of the school. The intervention program and modules were reviewed by an independent expert in the field of counseling and social work.

The RBGI is a group approach that aims to build and enhance resilience among victims of bullying by improving their capacity to sustain positive parent-child relationship, developing adaptive thinking and being involved in positive activities. The program used different techniques such as group sharing, reflective activities, creative narratives, cognitive homework and journal writing. The 8-session program also made use of social media utilities (such as Facebook and Twitter) as inspiration on the conduct of activities. After each session, outputs from the participants that reflected the outcome of each session was collected and included in the over-all discussion and presentation. The same form of CD-RISC was used to assess the usefulness of the intervention program by administering the tool for the students who participated in the series of resilience-based sessions after the conduct of the program.

\subsection{Method of Data Analysis}

To analyze the data from the survey forms, the researcher used descriptive analysis such as range, frequency and percentage, ranking, measure of central tendency, standard deviation and test of difference. Such analyses were helpful in describing the participants' socio-demographic characteristics, initial levels of resilience and the post-intervention results of such measures among the participants. For the data gathered from the focus-group discussions, the activity worksheets that the participants completed were collected by the researcher. Their verbal and written responses were documented, read and re-read, and the researcher identified major themes arising from their statements. The researcher created a coding scheme that best defined the identified topics or sub-topics. Such analysis was helpful in describing participants' responses related to the bullying experiences, as well as the reported outcomes as they participated on the resilience-based group sessions.

\section{Results}

This portion presents the two major parts of the result of the study such as the survey result which included the socio-demographic characteristics, bullying experiences and initial score on CD-RISC of the respondents. The second part presents the outcome of the resilience-based group intervention conducted to small group of participants.

\subsection{Socio-demographic characteristics}

This section presents the socio-demographic characteristics of students victimized by bullying, as well as the experiences related to bullying and the level of resilience during the initial administration of the CD-RISC. Table 1 presents the breakdown frequency and percentages of the respondents' socio-demographic characteristics such as age, sex and parental presence at home. Respondents of the study mostly came from 12 years old age group; more than half ( 43 or $60 \%$ ) of the students included in the study came from Grade 7 students since the academic coordinator of the school identified the grade level as needing the investigation and the intervention. The mean age of the study's respondents was 12.3 years old. Due to time constraints during the conduct of the survey and 
Tolentino, M., \& Suba, E.

the availability of students in the campus, the researcher and the teachers in charge decided to focus more on Grade-7 students which limited the researcher to analyze the distribution of bullying incidences across grade levels.

Table 1

Socio-demographic characteristics (SDC) of the respondents

\begin{tabular}{|c|c|c|}
\hline Variables & Frequency $(\mathrm{N}=72)$ & $\%$ \\
\hline \multicolumn{3}{|c|}{ 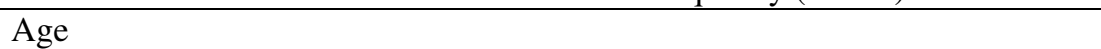 } \\
\hline 11 years old & 5 & 7 \\
\hline 12 years old & 43 & 60 \\
\hline 13 years old & 19 & 26 \\
\hline 14 years old & 5 & 7 \\
\hline \multicolumn{3}{|l|}{ Sex } \\
\hline Male & 16 & 22 \\
\hline Female & 56 & 78 \\
\hline \multicolumn{3}{|l|}{ Parental presence at home } \\
\hline Both parents & 43 & 60 \\
\hline Grandparents/aunts/elder sibling & 18 & 25 \\
\hline Mother only & 6 & 8 \\
\hline Father only & 4 & 6 \\
\hline
\end{tabular}

Using frequency count, the table shows that upon sample selection more female (56 or 78\%) were reported being bullied than males (16 or 22\%) identifying themselves as bullying victims. To determine the respondents' parental support at home, the researcher asked who among their parents were present at home. Most of the respondents (43 or 60\%) had their both parents at home. It was also worth noting that 25 percent of them were being taken care of adults other than their parents, such as grandmother, grandfather, aunt or elder sibling.

\subsection{Bullying victimization experiences}

Table 2 presents the types of bullying offenses that the respondents had experienced from the earliest point they can recall. To describe the participants' experiences as victims of bullying, multiple selections on the checklist of bullying offenses were completed by the respondents. Of the nineteen (19) forms of bullying offenses based on the existing literature, being given hurtful or insensitive alias/ name-calling was the most common experience cited by the respondents comprising the 72 percent of their responses. Further, the top five (5) most common experiences of bullying among the respondents were: being given hurtful alias/ name-calling, being laughed at (46 or 64\%), receiving insults/mockery (39 or 54\%), throwing of papers (33 or $46 \%$ ) and being given dirty looks ( 32 or $44 \%$ ).

The table classifies the bullying experiences reported by the respondents according to categories (physical, verbal and social) and presents the frequency count, percentage and ranking of each bullying experience. Under the physical category, the top three (3) bullying experiences of the respondents were being thrown of papers as first, being pushed intentionally $\left(2^{\text {nd }}\right)$ and being beaten $\left(3^{\text {rd }}\right)$. Under verbal bullying, the top three (3) bullying experiences of the respondents were being given hurtful alias ranking first, receiving insults or mockery $\left(2^{\text {nd }}\right)$ and being given dirty looks $\left(3^{\text {rd }}\right)$. Lastly on the social bullying, the top three bullying experiences among respondents are being laughed at as first, being extorted $\left(2^{\text {nd }}\right)$ and being subject of rumors $\left(3^{\text {rd }}\right)$.

To further inquire about other forms of bullying that the respondents experienced from bullies, an open-ended item was added. Some of the respondents had written the following offenses: being accused of a wrong-doing, getting angered, ridiculing one's surname, being humiliated in front of many people, and trashing one's bag. 
Table 2

List of bullying experiences of the respondents from the last 12 months

\begin{tabular}{|c|c|c|c|}
\hline Bullying Experiences & $\mathrm{F}$ & $\%$ & Rank \\
\hline \multicolumn{4}{|l|}{ Physical } \\
\hline Being thrown of papers or any object (batuhin ng papel o anumang bagay) & 33 & 46 & 1 \\
\hline Being pushed intentionally (itulak nang sinasadya) & 31 & 43 & 2 \\
\hline Being beaten (bugbugin) & 31 & 43 & 3 \\
\hline Hiding one's personal properties (itago ang personl na gamit) & 21 & 29 & 4 \\
\hline Theft (nakawan ng personal na kagamitan) & 19 & 26 & 5 \\
\hline Having spit on (duraan) & 8 & 11 & 6 \\
\hline Intentionally being kicked (sipain nang sinasadya) & 7 & 10 & 7 \\
\hline \multicolumn{4}{|l|}{ Verbal } \\
\hline Being given hurtful alias (bigyan ng masakit na alias) & 52 & 72 & 1 \\
\hline Receiving insults/mockery (insultuhin o bastusin) & 39 & 54 & 2 \\
\hline Being given dirty looks (tingnan nang masama) & 32 & 44 & 3 \\
\hline Receiving threats (pagbantaan) & 16 & 22 & 4 \\
\hline Being subjected on vandalism (isulat ang pangalan sa pader para bastusin) & 6 & 8 & 5 \\
\hline Receiving threats through text (pagbantaan sa text) & 5 & 7 & 6 \\
\hline \multicolumn{4}{|l|}{ Social } \\
\hline Being laughed at (pagtawanan) & 46 & 64 & 1 \\
\hline Being extorted (hingan ng pera para hindi masiraan sa iba) & 14 & 19 & 2 \\
\hline Being subject of rumors (pagchismisan sa personal) & 14 & 19 & 3 \\
\hline Being isolated from group (sinasadyang iwasan para magmukang kawawa) & 14 & 19 & 4 \\
\hline Being intimidated (takutin o pilitin na gawin ang isang bagay) & 11 & 15 & 5 \\
\hline Being bashed on social media (siraan gamit ang social media) & 7 & 10 & 6 \\
\hline
\end{tabular}

\subsection{Level of resilience before the resilience-based group intervention}

To determine the level of resilience among the respondents, descriptive statistics was used. From the CD-RISC instrument completed by the respondents, the mean of self-report resilience was obtained.

\section{Table 3}

The level of resilience of the respondents being victimized by bullying

\begin{tabular}{ccccc}
\hline & \multicolumn{2}{c}{ Resilience Level } \\
Median & $S D$ & Quartile Score & Percentile Score & Description \\
\hline 32 & 6.8 & $2^{\text {nd }}$ & 50 & Intermediate \\
\hline
\end{tabular}

The table shows that the mean score of 32 (6.8) represents the level of resilience among the sampled group of bullying victims in Sto. Domingo, Nueva Ecija, with scores ranging from minimum 14.0 to maximum score of 46.0. Based on the CD-RISC manual for scoring and interpretation, the mean score of 32 was on the $25-50^{\text {th }}$ percentile or second quartile $(\mathrm{Q} 2)$ score. This means that the group was on the intermediate level of resilience and that 50 percent of the population would score higher than them.

\subsection{Comparison of resilience scores across the respondents' SDCs}

To investigate resilience among bullying victims, the level of resilience is presented according to the respondents' socio-demographic grouping. Data regarding this are shown in Table 4. 
Tolentino, M., \& Suba, E.

\section{Table 4}

Comparison of resilience level across the socio-demographic groupings of the respondents

\begin{tabular}{lccc}
\hline \multicolumn{1}{c}{ Group } & $S D$ & Quartile Score (Percentile) & Description \\
\hline Age & $33(6.9)$ & $3^{\text {rd }}\left(75^{\text {th }}\right)$ & Intermediate \\
$11-12$ years old & $31(6.3)$ & $2^{\text {nd }}\left(50^{\text {th }}\right)$ & Intermediate \\
$13-14$ years old & & & \\
Sex & $30(9.1)$ & $2^{\text {nd }}\left(50^{\text {th }}\right)$ & Intermediate \\
Male & $33(5.8)$ & $3^{\text {rd }}\left(75^{\text {th }}\right)$ & Intermediate \\
Female & & & \\
& $32(6.4)$ & $2^{\text {nd }}\left(50^{\text {th }}\right)$ & Intermediate \\
Parental Presence & $33(7.8)$ & $3^{\text {rd }}\left(75^{\text {th }}\right)$ & Intermediate \\
Both parents & $28(5.9)$ & $1^{\text {st }}\left(25^{\text {th }}\right)$ & Low \\
Other adults & $34(7.2)$ & $3^{\text {rd }}\left(75^{\text {th }}\right)$ & Intermediate \\
Mother only & & & \\
Father only & & &
\end{tabular}

On the age groups' median scores comparison, the 11-12 years old group scored higher on resilience level ( $75^{\text {th }}$ percentile) than their 13-14 years old counterpart falling under the $50^{\text {th }}$ percentile. While the scores across different groups in the study did not vary in terms of its nominal descriptions, the differences on raw scores can also be worth noting. The table shows that the median score of resilience was higher on female $\left(75^{\text {th }}\right.$ percentile) than on male $\left(50^{\text {th }}\right.$ percentile) but still falling under the same description of intermediate level of resilience. It is also interesting to observe the marginal difference on the raw scores between groups living with both parents and those who live with other adults (grandparents, aunts and elder siblings). However, the group of respondents living with both parents had their raw scores falling on the $50^{\text {th }}$ percentile while their 'other-adult' group counterparts had their raw scores on resilience falling on the $75^{\text {th }}$ percentile. Meanwhile, those who were taken care of only by their mothers got the lowest median score of 28 , falling under the $25^{\text {th }}$ percentile.

\subsection{The outcomes of resilience-based group intervention}

The resilience-based group intervention had eight (8) sessions including the pre- and post-measure of resilience, rapport-building and resilience-focused activities. All modules were given Tagalog titles which were representatives of its purpose and objectives. This section presents the outcomes during the resilience-focused activities. The following tables present the summary of discussions during the group activities in relation to building supportive parent-child relationship and adaptive skills building. Specifically, the participants' view of their family through hashtags (a word or phrase preceded by a hash or pound sign \# used to identify messages on specific topic like that of Twitter or Facebook), the participants' feelings about their parents using emojies (small digital image or icon used to express an idea or emotion in electronic communication), the adaptive thoughts the group would start telling themselves, the group's learning outcomes, their behavioral plans and the matrix summary on the outcomes of the hashtags during the whole RBGI sessions.

\section{Table 5}

The participants' view of their relationship with family through hashtags

\begin{tabular}{lll}
\hline Pertaining to family love & \multicolumn{1}{c}{ Pertaining to parents } & \multicolumn{1}{c}{ Pertaining to their own feeling } \\
\hline \#magmahal (to love) & \#mapagmahalnamagulang (loving & \#ilovemyfamily \\
\#pagmamahalan (loving) & parents) & \#mahalnamahalkokayo (I love you \\
\#lovablefamily & \#supermomanddad & both) \\
& \#mapagbigaynamagulang (giving & \#happyfamilyandstrong \\
& parents) & \#namimisskonasila (I miss them) \\
& & \#imsoblessed \\
\hline
\end{tabular}

After reading the hashtags written by the participants, the researcher grouped them based on their common themes such as those that referred to familial love, their parents and their feelings towards their family. Such 
The use of resilience-based group intervention program for victims of bullying

hashtags provided clues about the participants' assessment of their family relationship. Also during the session, the researcher-facilitator instructed the group to identify emojies that represented how they felt about their parents.

\title{
Table 6
}

The participants' feeling about their parents through Facebook emojies

Emojie Translated Excerpt

\author{
Happy \\ Understanding and lovable, they keep us out of menace
}

Because I love my family and I am proud of them. I still can feel their love even when we are apart They teach me how to love others

We are not giving up on life's challenges because we love each other.

My parent is a loving parent even though she is away.

She is my first teacher.

It is sad since I do not have my parents beside me.

My parents teach me how to praise God and be a good boy

We always pray and hear masses together. I pray for the safety of my family.

They are always mad.

To creatively stimulate the participants' affective attitude towards their parents, the researcher-facilitator gave another task for the participants to identify emojies that represented their feelings towards their parents. Based on their answers, most of the participants identified emojies representing positive emotions such as heart, smiling, kissing with heart, book, praying hands which suggested their positive attitude towards their parents. Prominent reasons of such positive imageries were the love and support that they got from their parents notwithstanding the distance and the positive values they learned from them. However, some of the participants also used negative emojies such as sad and angry faces that reflected negative circumstance with their parents. The participants were allowed to select multiple adaptive thoughts for themselves. Such statements provided encouragement for them to be more adaptive in different life challenges.

In table 7, the top three (3) statements that most of the group members selected were (1) I can get through all the challenges and problems, (2) I can, and (3) I will not give up. Such statements were identified by the majority of the group members on the basis of their confidence about their respective family support and faith in God which were evident on the reasons of choosing such statements. Additionally, some participants mentioned their aspirations and control over problems as keys to overcoming life's difficulties. These were all evident on stated reasons of selecting the statements.

After processing the sharing made by the group, the researcher-facilitator closed the session by instructing the participants to select from among their classmates and give them one or two empowering self-statements. Six 
Tolentino, M., \& Suba, E.

(6) individuals received empowering statements from the group especially those who were known to be in current difficult situation. Participants also received encouraging messages of faith and perseverance from the group members.

\section{Table 7}

The adaptive thoughts identified by the group

\begin{tabular}{lll}
\hline \multicolumn{1}{c}{ Statements } & Frequency & \multicolumn{1}{c}{ Reasons } \\
\hline $\begin{array}{l}\text { I can get through all the } \\
\text { challenges and problems. }\end{array}$ & 6 & $\begin{array}{l}\text { If others can, so can I. There are many people that love me that when I know } \\
\text { I can. } \\
\text { Because I know that God is always on my side, and that I have my family } \\
\text { and friends to confide in with my problems, } \\
\text { Even there are times that I get tired of the problems. }\end{array}$ \\
& $\begin{array}{l}\text { There will be a day that the bullies will stop. For myself and my family, I can } \\
\text { do it. } \\
\text { This is what I often tell myself when I feel so overwhelmed with what } \\
\text { happen to my life. }\end{array}$
\end{tabular}

I will not give up. $\quad 5 \quad$ Giving up is like losing the trust in myself.

This is just one challenge that I can overcome.

Because I still have many aspirations.

It's difficult but

4

I will not give up for there are people that loves me.

manageable.

I am not stupid.

I possess intelligence, otherwise I will not achieve my dreams. I know in myself that I can make it.

There are people that can 1 help me.

Like family. They can help me to be strong despite my experience as victim

It is so good to live!

Someday they will be proud of me.

The Lord is always by my $\quad 1$ side. of bullying. 1 They cannot bring me down just with their words.

Because whatever happens, I can make it until they regret with what I will achieve.

Because I know that He will not let me stumble on my feet. He will show and get me in the right path.

The group also discussed the important insights and attitudes that they learned as the intervention was running. The following insights and learning were quoted from their responses.

\section{Table 8}

Learning outcomes from the resilience-based group intervention as mentioned by the participants

\begin{tabular}{l|l}
\hline \multicolumn{1}{c|}{ Being Resilient } & \multicolumn{1}{c}{ Being Well-connected } \\
\hline It seems that I got stronger and my heart felt light. & $\begin{array}{l}\text { The important thing I learned in the program is how to } \\
\text { express love and gratitude through expressive activities like } \\
\text { drawing and writing }\end{array}$ \\
$\begin{array}{l}\text { I learned how to fight, to overcome things that bother me. I } \\
\text { learned how to be compassionate. }\end{array}$ & $\begin{array}{l}\text { I realized that we need to help each other and never lose } \\
\text { hope. }\end{array}$ \\
$\begin{array}{l}\text { I learned that I need to be resilient, to be more positive to } \\
\text { whatever is happening. }\end{array}$ & $\begin{array}{l}\text { I learned that loving one's parent is important, and do not put } \\
\text { others down. }\end{array}$ \\
$\begin{array}{l}\text { I learned to overcome shyness, and be more mindful about } \\
\text { my actions, and become stronger. }\end{array}$ & $\begin{array}{l}\text { Being a good person to others, being more sensitive whether } \\
\text { you are hurting others already. }\end{array}$ \\
\hline
\end{tabular}

The researcher-facilitator classified the learning outcomes from the intervention as reported by the 
The use of resilience-based group intervention program for victims of bullying

participants during the focus group discussion. Mostly, the participants mentioned that the group intervention had encouraged them to be more resilient and stay determined despite life difficulties. Most of the participants also cited learning that related to building rewarding and considerate relationships with parents and others. The facilitator also asked a situational question for the group to determine the kind of behavior they planned to manifest when confronted by adversities like bullying in the future. The following were their responses.

Table 9

The participants' behavioral plan when faced with bullying problems in the future

\begin{tabular}{l|l|l|l}
\hline \multicolumn{1}{c|}{$\begin{array}{c}\text { Hardiness } \\
\text { (Pagiging Matibay) }\end{array}$} & \multicolumn{1}{c|}{$\begin{array}{c}\text { Self-Control } \\
\text { (Pagtitimpi) }\end{array}$} & \multicolumn{1}{c}{$\begin{array}{c}\text { Faith } \\
\text { (Pananalig) }\end{array}$} & \multicolumn{1}{c}{$\begin{array}{c}\text { Connectedness } \\
\text { (Pakikipag-Ugnayan) }\end{array}$} \\
\hline $\begin{array}{l}\text { I will not mind those belittle me, and } \\
\text { believe in God. }\end{array}$ & $\begin{array}{l}\text { I will be stronger and put } \\
\text { trust in myself. }\end{array}$ & $\begin{array}{l}\text { I will pray to God to } \\
\text { help me get through the } \\
\text { problems that I } \\
\text { encounter.” }\end{array}$ & $\begin{array}{l}\text { I will now tell my parents } \\
\text { about my worries to get } \\
\text { support from them. }\end{array}$ \\
$\begin{array}{l}\text { I will never } \\
\text { acknowledge the bullies } \\
\text { and find time to } \\
\text { strengthen myself. }\end{array}$ & $\begin{array}{l}\text { I will always calm down. } \\
\text { I will settle things through } \\
\text { diplomatic discussion. } \\
\text { Never cry easily. }\end{array}$ & $\begin{array}{l}\text { I will not be stronger, } \\
\text { because God is always } \\
\text { there. }\end{array}$ & $\begin{array}{l}\text { I will never get } \\
\text { discouraged by problems } \\
\text { and challenges because I } \\
\text { know that my parents are } \\
\text { there to guide me. }\end{array}$ \\
$\begin{array}{l}\text { I will not recognize what } \\
\text { the bullies are saying } \\
\text { about me. I will be } \\
\text { happy and brave in spite } \\
\text { of the challenges and } \\
\text { hardships. }\end{array}$ & $\begin{array}{l}\text { Be positive so that I will } \\
\text { never get sad about my } \\
\text { hardships in my life. }\end{array}$ & $\begin{array}{l}\text { I will recognize that God } \\
\text { is there to guide and } \\
\text { help me overcome my } \\
\text { problems. }\end{array}$ & \\
\hline
\end{tabular}

Based on the responses given by the participants during the group discussion, the researcher- facilitator classified into four (4) how the participants would confront future trials based on what they learned from the resilience-based group intervention. The participants mentioned that they would refuse to be affected when being bullied (hardiness). They would exercise self-control by not getting easily angered and calming themselves if being bullied. Also exercising faith and spirituality among the group was consistently being cited as their means to overcome future struggles like bullying. Lastly, the participants planned to build open relationship with their parents and trusted significant others to buffer the negative effects of bullying. The result of the focus group discussion reflects the similar finding from the study of Orio (2016) which suggested that optimism, sense of coherence, hardiness and religiosity or spirituality coping are indicators of resilience among Filipinos, especially those who have experienced natural disaster like typhoon.

\subsection{Summary of the outcome of resilience-based group intervention for victims of bullying}

The table presents the summary of the RBGI regarding the methods and observed outcomes from each session of the intervention. The table also presents the over-all impact of the RBGI to the group participants as observed by the researcher-facilitator. Sessions which used specified methods were presented with their corresponding outcomes to the group. The goals of the resilience-based group intervention program was to help the participants gain knowledge and attitude important on building supportive parent-child relationship, adaptive-skills and becoming involved in positive activities. Such personal developments were assumed to be important in enhancing the participants' general resilience.

Using the created resilience-based modules, the researcher aimed to address the participants' need to develop supportive parent-child relationship, practice healthy cognitions about oneself and be provided with 
Tolentino, M., \& Suba, E.

positive activities with their peers. The rapport-building session, creative exercises and group sharing sessions provided the participants with enjoyable experience with their peers and paved way for more open social atmosphere among the members. The fourth session about parent-child relationship involved homework or task which provided them opportunity to practice open and warm communication with their parents. The fifth session on adaptive-skills provided the participants with skills on short meditation that can be useful buffer against stressful situations. The session also encouraged the group to empower themselves with positive thoughts and enabled them to empower others.

\section{Table 10}

Matrix summary on the observed outcomes of RBGI sessions

\begin{tabular}{clc}
\hline Session & \multicolumn{1}{c}{ Methods } & \multicolumn{1}{c}{ Observed Outcome } \\
\hline 1. Pre-intervention Resilience Survey & $\begin{array}{l}\text { Group administered survey of } \\
\text { resilience using CD-RISC }\end{array}$ & $\begin{array}{l}\text { Respondents were able to reflect and be aware } \\
\text { of their own resilience by taking the survey. }\end{array}$
\end{tabular}

2. "Makipagkaibigan"

(Rapport-building Activity)

3. "Maging Matatag" (Activity on the Group's Concept of Resilience)

4. "Unawain ang mga Pagsubok" (Group Discussion on Bullying Experiences)

5. "Pahalagahan ang Pamilya" (Group Activity on Parent-Child Relationship)

6. "Tulungan ang Sarili"

(Activity on Adaptive Skill Building)

7. "Laging Piliin Maging Matatag" (Discussion on the Group's Learnings and Insights)

8. Post-intervention measure of resilience
Group discussion about the concept of resilience using drawing materials.

Reflective and creative activity with discussions about their problems on bullying victimization

Creative tasks and Twitter and Facebook-inspired group activity

Written exercise and group discussion about positive self-talk and adaptive thinking. Basic relaxation techniques and deep breathing.

Written reflections and group sharing on their learning and insights about the program.

Administration of CD-RISC survey to participants who completed the intervention program.
The facilitator obtained personal preferences, habits and interests of the group in the same way that participants get to know their group mates better. Sharing of opinions and preferences made the participants become more involved with the group.

The group explored and shared their own concept of a resilient youth. The group understood the important elements of resilience such as being in control with one's situation, having aspirations and building meaningful social connections.

The group were taught to bravely confront their past hurtful experiences as bullying victims and understand the importance of social or family support in overcoming such challenge. Creative tasks helped the group to recall, explore and express their feelings about the experience.

The group were able to assess their own family support and understand the importance of being open to their parents. The group come up with plans on expressing gratitude, apologies, appreciation, love and aspirations to their parents.

The group were taught simple techniques in relieving tensions when confronted with stressful situation. The group were trained to use positive and empowering statement about oneself. They were also provided opportunity to give such encouragement to their group-mates.

The group evaluated their learnings from previous sessions and shared how the lessons would help them in the future. They were able to generate simple behavioral and attitudinal plans in case that they might encounter challenges in the future.

The researcher-facilitator was able to compare the difference on the score of resilience before and after the RBGI. 


\subsection{Difference between the scores on CD-RISC before and after the RBGI}

The resilience-based group intervention (RBGI) was conducted to a group of high school students who were victimized by bullying. The 8 -session intervention included fifteen (15) participants but only nine (9) were able to complete the program from pre-intervention measure to post-intervention of resilience. The researcher took note of the participants' initial levels of resilience scores based on CD-RISC and compared them to the scores they obtained on the same test after participating on the resilience-based group intervention. This part presents the outcome of the resilience-based group intervention by measuring the differences on the resilience scores of the respondents before and after the intervention using the CD-RISC 10.

\section{Table 11}

Comparisons of scores on CD-RISC 10 scale of resilience before and after the intervention

\begin{tabular}{lcc}
\hline Group & Pre-intervention Score & Post-intervention Score \\
\hline Participant 1 & 13.00 & 10.00 \\
Participant 2 & 14.00 & 22.00 \\
Participant 3 & 14.00 & 40.00 \\
Participant 4 & 12.00 & 22.00 \\
Participant 5 & 12.00 & 28.00 \\
Participant 6 & 13.00 & 26.00 \\
Participant 7 & 14.00 & 29.00 \\
Participant 8 & 13.00 & 36.00 \\
Participant 9 & 18.00 & 19.00 \\
Median & 14.00 & 26.00 \\
\hline
\end{tabular}

To determine whether the resilience-based group intervention generated an improved score on the participants' resilience score on CD-RISC, the researcher compared the individual scores obtained by the participants before and after the conduct of the intervention. Results showed that 8 out of 9 or $88 \%$ of the respondents increased the score obtained on the resilience scale after intervention. The increase on scores ranged from the minimum 1-point increase (i.e. from 18 to 19) to the maximum difference of 26-point increase on the post-intervention test (i.e., from 14 to 40). The median scores of pre- and post-intervention measure of resilience obtained by the group were also indicated on the table.

To further determine the significance of observed differences on the resilience scores, the researcher tested the difference using the paired-sample t-test.

\section{Table 12}

Statistical difference on the scores by the participants before and after the resilience-based group intervention

\begin{tabular}{|c|c|c|c|c|c|}
\hline & Mean & $S D$ & $d f$ & $\mathrm{t}$-value & $p$ \\
\hline Pre-intervention & 13.66 & 1.80 & 8 & 3.860 & $.005 * *$ \\
\hline Post-intervention & 25.77 & 8.98 & & & \\
\hline
\end{tabular}

Note. **highly significant $(p \leq .005)$

The table shows that the mean score on CD-RISC taken by the participants after the intervention was significantly different $(\mathrm{t}=3.860 ; p=.005)$ from their previous mean score on the same test taken before the intervention, with 95 percent confidence level. Also, the mean difference on observed scores among the participants was 12.11. Therefore, the study's hypothesis that there was no significant difference on the levels of resilience among the participants before and after the RBGI was rejected.

The stated learning outcomes of the group participants from the RBGI sessions and the improved scores on their resilience using the CD-RISC showed that the intervention created and conducted by the researcher was useful in building resilience among the students who were victimized by physical, social and verbal bullying in Sto. Domingo, Nueva Ecija. This further established the importance of three factors such as supportive parent-child relationship, adaptive skills and positive activities on building youth resilience like what past 
empirical evidences had shown (Engle, Castle \& Menon, 1996; Newman, 2002; Drapeau et al., 2007; Center on the Developing Child, 2015). Wade (2007) concluded that being optimistic, using productive coping strategies, possessing social skills and perceiving a high level of social support in life provided victims protective buffer against ill effects of bullying. This was particularly observed on the outcomes of the study.

\section{Discussions}

The result of the study supported the findings of UNICEF-Philippines (2016) that female students reported to be victims of peer violence in school more than their male counterparts. This result seemed to be consistent with findings from other countries that female students reported higher percentages of personal and online victimization (Hinduja \& Patchin, 2010) as well as the degree of emotional vulnerability of bullying incidences (Hinduja \& Patchin, 2009).

The results ranked the most common forms of bullying among Grade 7 and 8 students which are: being given hurtful alias, dirty looks, receiving insults/mockery, being thrown of papers, and being laughed at. William and Guerra (2007) and Council for the Welfare of Children and UNICEF Philippines (2016) grouped bullying offenses into their common forms. Based on the classifications provided by Williams and Guerra (2007), being given hurtful alias and dirty looks, and receiving insults/mockery were considered as verbal bullying or aggression; while being thrown of papers was considered as physical type of bullying. Also, being laughed at was a form of social bullying among school-aged youth according to the Council for the Welfare of Children and UNICEF Philippines (2016). The result is found to be consistent with the study of Williams and Guerra (2007) wherein verbal forms of bullying remains to be the most highly experienced peer aggression among middle high school students.

According to the National Scientific Council on the Developing Child (2015) and VicHealth (2015), resilience is defined as the capacity of an individual to adapt well on adversity and life stresses. Based on the quartile score of resilience among the students in Santo Domingo Nueva Ecija, respondents had relatively low average level of capacity in adapting to adversity and life stresses. To Greenberg (2006), such resilience capacity was broadly attributed to three factors such as the individual characteristics, the quality of the child's relationships as well as broad ecological factors, which was included in the objectives of the resilience-based group intervention program. Similar to the children from impoverished condition studied by Gebru (2009), victims of bullying in Sto. Domingo, Nueva Ecija also seemed to implement ways to cope with hostile peer experiences using their personal assets and resources.

The findings of Newsome, Vaske, Gehring, and Boisvert (2015) were consistent with the results showing that females exhibited greater resilience than males. The overall conclusion from the authors was that environmental factors can explain such difference. On the other hand, the finding of this present study was different from the result of previous research wherein males tend to be less distressed than female as they experienced bullying victimization (Sapouna \& Wolke, 2013). It is also interesting to observe the marginal difference on the raw scores between groups living with both parents and those who live with other adults (grandparents, aunts and elder siblings).

The result found out that the respondents who live with both parents have intermediate level of resilience based on CDRISC. Tiongco (2010) argued that a student who had a complete family was more likely to show favorable behavior in social context. Interestingly, most of the respondents had both parents living with them at home which safely suggested that the students had ready and available adult support and care at home. The finding that respondents being taken care of other adults (such as grandparents, auntie and elder siblings) obtained the highest median score of 33 challenged the research evidence that children who were raised by their grandparent were at risk for having psychological problems (Dunifon, 2013). There was much to investigate regarding how such kind of child-raising generally affect youth's well-being and resilience. The surprisingly low level of resilience among the respondents who were singlehandedly taken care of by their mother may be due in 
part on the fact that mothering can be particularly demanding for single women who were more vulnerable to a variety of risks such as economic hardship which could lead to poor relational functioning in the family. According to Taylor and Conger (2017), such risks placed their children at higher risk of experiencing maladjustment. The municipality of Sto. Domingo is known to be a rural farming community wherein limited opportunities are accessed by single mothers who have to provide for their children's needs and education. This can be a good area to investigate further whether single parenthood has negative impact on building or enhancing youth resilience. This area can be explored well on future studies since according to the research of Wade (2007) youth who demonstrated resilience can be partly attributed to perception of high level of social support in one's life.

The resilience-based group intervention program created by the researcher was able to build proper rapport among the group, capture their own concept of resilience, process their past experiences on bullying victimization, have them assessed their family and parental support, and enhance their adaptive thinking skills. The millennial-inspired rapport building activity was effective in building pleasant atmosphere among the group because of its positive and encouraging effect to the group and in boosting the presumably damaged self-esteem of the group due to bullying victimization experience. Also the social media graphic icons (such as Twitter, Facebook and Instagram) designed on each activity worksheets helped improved the group's participation on narrating and expressing their thoughts and experiences. The reflective exercises during the activities provided them venue to explore their past experiences, current situation and their personal views. Also, the creative narrative activities as main techniques in group activities allowed them to express such reflections using fun and modern means which was fit to millennial group of participants. This is consistent with the findings of Safaria and Yunita (2014) who conducted art therapy to victims of bullying and found that art expression decreased the level of anxiety for the experimental group after the 5-session art therapy. This further validated the notion that young participants require discussion methods that permitted them to express themselves using their imaginative resources.

More importantly, the mean score on CD-RISC 10 taken by the participants after the intervention was significantly different $(\mathrm{t}=3.860 ; p=.005)$ from their previous mean score on the same test taken before the intervention, with $95 \%$ confidence level. Also, the mean difference on observed scores among the participants was 12.11. With the help of the resilience-based group intervention program, the initial level of self-report resilience significantly increased as found on repeated measures of CD-RISC among the participants.

\section{Conclusions and recommendations}

Grade 7 and Grade 8 students in Julia Ortiz Luis National High School recalled experiences of bullying victimization in forms of physical, verbal and social bullying. They had self-report average level of resilience according to the results of Connor-Davidson Resilience Scale. Concept of resilience among bullying victims was found to be anchored on one's supportive family relationship, adaptive thinking and skills, how one practiced his own faith in God, and the presence of future aspirations. Group approach in building resilience among youth victimized by bullying was found to be a doable and viable school intervention. The use of reflective exercises and creative narratives provided non-intrusive and light discussions yet capable of helping the participants explore their thoughts, instill knowledge and promote attitude-change among the group. Infusing millennial-inspired techniques on group sessions was facilitative on enhancing participation. The RBGI showed potential impact of developing spirituality, self-control and hardiness against bullies, and encouraging supportive parent-child relationship among its participants. With proper intervention from education and mental health advocates, adverse effect of bullying victimization among youth can be turned into more positive and meaningful goals which could motivate them to seek and maintain supportive family relationship, practice self-empowerment, develop spirituality and keep their aspirations.

School authorities must continuously devise mental health intervention such as resilience-building programs for victims of school violence and address the occurrences of physical, verbal and social bullying that are 
experienced by the victims and perpetrated by bullies. Since teenage depression is increasing, it is now imperative for parents, church and school workers to look after the mental well-being of youth and capacitate them for future challenges altogether by capitalizing on the sources of resilience among youth. Aside from public and private schools, government and non-government agencies can also conceptualize a resilience-based group intervention as helpful activities for youth who have experienced other traumas such as natural disaster, domestic violence and war-related incidences. Class advisers and guidance counselors can adopt or employ the group approach and the millennial techniques used in the resilience-based group intervention as group activities for helping their students overcome wide array of adversities.

To establish the evidence-based applicability of the group intervention program used in this study, interested researchers must also include other measures or indicators in assessing the impact the resilience-based group intervention program. They might also be interested to investigate how the program would help in improving academic performance and social competence of students, aside from enhancing the perception of their resilience.

Acknowledgement: Our appreciation and acknowledgment for the following advisory and examining committee members who helped the authors improve the quality of the paper. Prof. Irene G. Bustos, Prof. Milagros Santos, Prof. Rosario Quicho, Prof. Hiyasmin Malicdem- Delos Santos from the College of Education, CLSU.

\section{References}

Alvord, M., \& Grados, J. (2005). Enhancing resilience in children: A proactive approach. Professional Psychology: Research and Practice, 36(3), 238-245. https://doi.org/10.1037/0735-7028.36.3.238

Ancho, I. V. (2014). School violence in the Philippines: A study on programs and policies. Retrieved from https://www.onlinepresent.org/vol36_2013/7.pdf

Atlas, M., \& Pepler, J. (2001). Bullying victimization in youth and mental health problems: Much ado about nothing? Psychological Medicine, 29, 1-3.

Barbero, J., Hernandez, J., Esteban, B., \& Garcia, M. (2012). Effectiveness of anti-bullying school programs: A systematic review by evidence levels. Children and Youth Services Review, 34(9), 1646-1658. https://doi.org/10.1016/j.childyouth.2012.04.025

Bibou-Nakou, I, Tsiantis, J., Assimopoulos, H., Chatzilambou, P., \& Giannakopoulou, D. (2012). School factors related to bullying: A qualitative study of early adolescent students. Social Psychology of Education, 15(2), 125-145. https://doi.org/10.1007/s11218-012-9179-1

Bickmore, K. (2011). Policies and programming for safe schools: Are anti-bullying approaches impeding education for peace-building? Educational Policy, 25, 648-687. https://doi.org/10.1177/0895904810374849

Cardona, R. S., Reyes, A. S., \& Tangalin, M. M. (2015). The bullying experiences and classroom discipline techniques in an urban national high school in the Philippines: A basis for an anti-bullying program. American International Journal of Contemporary Research, 5(2), 49-52.

Center on the Developing Child. (2015). The science of resilience, in brief. Retrieved from https://developingchild.harvard.edu

Connor, K. M., \& Davidson, J. R. T. (2003). Development of a new resilience scale: The Connor-Davidson Resilience Scale (CD-RISC). Depression and Anxiety, 18(2), 76-82. https://doi.org/10.1002/da.10113

Cook, C., Williams, K., Guerra, N., Kim, T., \& Sadek, S. (2010). Predictors of bullying and victimization in childhood and adolescence: A meta-analytic investigation. School Psychology Quarterly, 25(2), 65-83. https://doi.org/10.1037/a0020149

Council for the Welfare of Children and UNICEF Philippines. (2016). National baseline study on violence against children: Philippines, executive summary. Retrieved from https://www.unicef.org/philippines

Department of Education. (2017). DepEd iterates zero tolerance policy vs child abuse, bullying. Retrieved from 
The use of resilience-based group intervention program for victims of bullying

http://www.deped.gov.ph/press-releases/deped-iterates-zero-tolerance-policy-vs-child-abuse-bullying.

Drapeau, S., Saint-Jacques, M., Lepine, R., Begin, G., \& Martin, B. (2007). Processes that contribute to resilience among youth in foster care. Journal of Adolescence, 30(6), 977-999.

https://doi.org/10.1016/j.adolescence.2007.01.005

Dray, J., Bownan J., Wolfenden, L., Campbell, E., Freund, M., Hodder, R., \& Wiggers, J. (2017). Systematic review of universal resilience interventions targeting child and adolescent mental health in the school setting. Journal of the American Academy of Child \& Adolescent Psychiatry, 56(10), 813-824. https://doi.org/10.1016/j.jaac.2017.07.780

Dunifon, R. (2013). The influence of grandparents on the lives of the children and adolescents. Child Development Perspectives, 7(1), 55-60. https://doi.org/10.1111/cdep.12016

Engle, P.L., Castle, S., \& Menon, P. (1996). Child development: Vulnerability and resilience. https://doi.org/10.1016/0277-9536(96)00110-4

Flores, H. (28 July 2014). 1,700 cases of bullying reported. Retrieved from http://www.philstar.com/metro/2014/07/28/1351137/1700-cases-bullying-reported

Fonzi, A., Genta, M. L., Menesini, E., Bacchini, D., Bonino, S., \& Costabile, A. (1999). Italy. In P. K. Smith, Y. Morita, J. Junger-Tas, D. Olweus, R. F. Catalano, \& P. T. Slee (Eds.), The nature of school bullying: A crossnational perspective (pp. 140-156). London: Routledge.

Gebru, B. T. (2009). Looking beyond poverty: Poor children's perspectives and experiences of risk, coping and resilience in Addis Ababa [Doctoral dissertation]. University of Bath.

Gerardo, J. U. (2016, October 3-4). Types, extent, and effects of bullying on the well-being of students in Western Cagayan. Paper presented at the $13^{\text {th }}$ National Convention of Statistics. Philippines.

Greenberg, M. (2006). Promoting resilience in children and youth: Preventive interventions and their interface with neuroscience. New York Academy of Sciences, 1094, 151-163. https://doi.org/10.1196/annals.1376.013

Hall, D. K. (2010). Compendium of selected resilience and related measures for children and youth. The Child and Family Partnership. Toronto, Canada. Retrieved from https://www.reachinginreachingout.com

Hechanova, M., Waelde, L., Docena, P., Alampay, L., Alianan, A., Flores, M., Ramos, P., \& Melgar, M. (2015). The development and initial evaluation of Katatagan: A resilience intervention for Filipino disaster survivors. Philippine Journal of Psychology, 48(2), 105-131.

Hepburn, A. (1997). Teachers and secondary school bullying: A postmodern discourse analysis. Discourse \& Society, 81(1), 27-48. https://doi.org/10.1177/0957926597008001003

Hinduja, S., \& Patchin, J. W. (2009c). Cyberbullying: Emotional and psychological consequences. Retrieved from https://cyberbullying.org/cyberbullying

Hinduja, S., \& Patchin, J. W. (2010b). Cyberbullying by gender. Cyberbullying research center. Retrieved from http://www.cyberbullying.us/2010_charts/cyberbullying_gender_2010.jpg

Kumpulainen, J., Nation, A., Tracy, G., Melton, B., \& Flerx, V. (1999). Implementation of the Oweus Bullying Prevention Program in the Southeastern United States. In P. K. Smith, D. Pepler, \& K. Rigdy (Eds.), Bullying in schools: How successful can interventions be? (pp. 55-79). Cambridge University Press.

Lemoine, K., \& Labelle, J. (2014). What are effective interventions for building resilience among at-risk youth? Retrieved from https://www.peelregion.ca/library/pdf

Luthar, S., \& Cicchetti, D. (2000). The construct of resilience: Implications for interventions and social policies. Developmental Pathology, 12(4), 857-885. https://doi.org/10.1017/S0954579400004156

National Scientific Council on the Developing Child. (2015). Supportive relationships and active skill-building strengthen the foundations of resilience: Working paper 13. Retrieved from http://www.developingchild.harvard.edu

Newman, T. (2002). Promoting resilience: A review of effective strategies for child care services. Retrieved from https://www.cumbria.gov.uk/content/internet

Newsome, J., Vaske, J., Gehring, K., \& Boisvert, D. (2015). Sex differences in sources of resilience and vulnerability to risk for delinquency. Journal of Youth and Adolescence, 45(4), 730-745. https://doi.org/10.1007/s10964-015-0381-2 
Tolentino, M., \& Suba, E.

Notario-Pacheco, B., Martinez-Vizcaino, V., Trillo-Calvo, E., Perez-Yus Mc, Serrano-Parra, D., Garcia-Campayo, J. (2014). Validity and reliability of the Spanish version of the 10-item CD-RISC in patients with fibromyalgia. Health and Quality of Life Outcomes, 12(14). https://doi.org/10.1186/1477-7525-12-14

Orio, T. R. (2016). Exploring the intrinsic indicators of individual resiliency. International Journal of Research Studies in Psychology, 5(2), 15-30. https://doi.org/10.5861/ijrsp.2016.1374

Orpinas, P., \& Home, A. (2005). Bullying prevention: Creating a positive school climate and developing social competence. Retrieved from https://www.apa.org/pubs/books/4317082.aspx

Perry, W., Hudges, B., \& Edgar, S. (2001). How schools tackle bullying and the use of whole school policies. Changes over the last decade. Educational Psychology, 28, 663-676.

Reyes, F. (2012). Correlates of bullying among pupils in two public elementary schools: Basis for a social adjustment program [Unpublished masteral thesis]. Central Luzon State University, Science City of Munoz, Nuvea Ecija, Philippines.

Rodkin, F., \& Berger, C. (2008). Types of bullying behaviors and their correlates. Aggressive Behavior, 20, 359-368.

Ross, D. (2002). Bullying. In the Handbook of crisis counselling, intervention, and prevention in the schools (2nd ed., pp. 105-135): Mahwah, NJ: L. Erlbaum Associates.

Rossouw, P. (2016). The predictive 6-factor resilience scale: Neurobiological fundamentals and organizational application. Retrieved from http://www.neuropsychotherapist.com/the-predictive-6-factor-resilience-scale

Rutter, M. (1997). An update on resilience: Conceptual considerations and empirical findings. New York: Cambridge University Press.

Safaria, T., \& Yunita, A. (2014). The efficacy of art therapy to reduce anxiety among bullying victims. International Journal of Research Studies in Psychology, 4(4), 77-88. https://doi.org/10.5861/ijrsp.2014.829

Sapouna, M., \& Wolke, D. (2013). Resilience to bullying victimization: The role of individual, family and peer characteristics. Child Abuse Neglect, 37(11), 997-1006. https://doi.org/10.1016/j.chiabu.2013.05.009

Swearer, G., \& Doll, G. (2001). Bullying as a group process: An adaptation of the participant-role approach. Aggressive Behavior, 48, 577-582.

Taylor, Z. E., \& Conger, R. D. (2017). Promoting strengths and resilience in single-mother families. Wiley Online Library. https://doi.org/10.1111/cdev.12741

Tiongco, G. D. (2010). Effects of parenting styles and classroom discipline techniques on pupil's behavior in selected elementary schools of Calamba West District, Laguna. Retrieved from https://www.koha.nlp.gov.ph/opac-ISBDdetail

Underwood, D., \& Rosen, A. (2011). Bullying and aggression among youth. In K. Sexton-Radek (Ed.), Violence in schools: Issues, consequences and expressions (pp. 121-144). Praeger Publishers.

Ungari, M., Russell P., \& Connelly, G. (2014). School-based interventions to enhance the resilience of students. Journal of Educational and Developmental Psychology, 4(1), 66-83. https://doi.org/10.5539/jedp.v4n1p66

Vallejos, J. (2011). Boy killed in school brawl in N. Ecija. Retrieved from http://news.abs-cbn.com/nation/regions/12/02/11/boy-killed-school-brawl-n-ecija

Vichealth. (2015). Interventions to build resilience among young people: A literature review. Retrieved from http://trove.nla.gov.au/work/214568270?selectedversion=NBD58845993

Wade, E. L. (2007). Resilient victims of school bullying: Psychosocial correlates of positive outcomes. Retrieved from http://researchbank.rmit.edu.au/eserv/rmit:6389/

Wang, L., Shi, Z., Zhang, Y., \& Zhang, Z. (2010). Psychometric properties of the 10-item Connor-Davidson Resilience Scale in Chinese earthquake victims. Psychiatry and Clinical Neurosciences, 64(5), 499-504. https://doi.org/10.1111/j.1440-1819.2010.02130.x

Williams, K. R., \& Guerra, N. G. (2007). Prevalence and predictors of Internet bullying. Journal of Adolescent Health, 41(6), 14-21. https://doi.org/10.1016/j.jadohealth.2007.08.018 